U.S. Department of the Interior U.S. Geological Survey

\title{
LOUISIANA COASTAL GEOGRAPHIC INFORMATION SYSTEM NETWORK YEAR TWO FINAL REPORT
}

by

Donald W. Davis', Matteson W. Hiland ${ }^{1}$, and Randolph A. McBride ${ }^{1}$

S. Jeffress Williams ${ }^{2}$

USGS Science Officer and Editor

\section{Open-File Report 92-424}

This report was prepared under contract to the U.S. Geological Survey and has not been reviewed for conformity with USGS editorial standards or with the North American Stratigraphic Code. Opinions and conclusions expreseed herein do not necesearily represent those of the USGS. Any use of trade, product, or firm names is for descriptive purposes only and does not imply endorsement by the U.S. Government.

\footnotetext{
${ }^{1}$ Louisiana Geological Survey, Box G, Univervity Station, Baton Rouge, LA 70893

U.S. Geological Survey, 914 National Center, Reaton, VA 22092
} 


\section{ABSTRACT}

The purpose of the Louisiana Coastal Geographic Information System Network (LCGISN) is to identify and capture geographical material and consolidate it into an easily retrievable form, despite different formats, hardware platforms, software, and storage methods. This will enable individuals to receive information traditionally unavailable. The network uses a distinctively different approach for identifying and dispensing geographic information and is not limited to a single medium. It is designed to link all data mediums into a coherent structure for sharing geographically referenced information. Linking original programming with existing GIS software and an industry standard relational database management system will provide users the capability to search for data references by interactively defining an area of interest on a digital base map. Several agencies will have access through the network to a wide variety of information.

Numerous decisions have been made concerning the user community's ability to search for data references by interactively defining the area of interest. To provide this function, menus are being developed for specifying data format conversions, projection and datum transformations, and storage and retrieval of several of the most commonly used coastal data sets. The 65 menus under development will allow the user to set search criteria by selecting parameters from a series of menu-driven options. The system will return any, or all of the following: a list of digital maps or imagery that can be displayed, a list of maps or remotely sensed data and information on their availability, and a list of bibliographic references concerning the area and subject defined.

The Technical Group, working cooperatively with LCGISN administrative personnel, focused on a number of technical, mapping, outreach, and procedural issues. The most significant accomplishments are as follows: 1) menu interface development was initiated using Intergraph I-Forms software; 2) after considerable discussion and analysis, Modular GIS Environment (MGE) using the Oracle relational data base was selected as the operational GIS; 3) bibliographic and cataloging issues have been discussed with members of the LSU library staff; 4) numerous foundations have been contacted as possible sources of external funding; 5) in April 1991, the first LCGISN Newsletter was published; 6) members of the Technical Group attended numerous technical meetings and conferences, either as presenters or participants; 7) contours on the Madisonville 7.5-min. quadrangle maps were digitized according to USGS specifications; 8) from this effort, an intergovernmental work-share agreement was signed between the Louisiana Geological Survey and the U.S. Geological Survey Mid-Continent Mapping Center, National Mapping Division to digitize the contours on the $\mathbf{3 1 0}$ maps that comprise Louisiana's coastal zone; 9) interaction with organizations that use and generate digital data sets is continuing; and 10) planning for the semi-annual Management Council meetings and the Eighth Annual RS/GIS Workshop is in progress. 


\section{ACKNOWLEDGEMENTS}

Members of the GIS Technical Group and the Management Council are thanked for their collective efforts in insuring the success of this project. We would also like to acknowledge the numerous Federal, State, and local agencies that have inquired about the system and agreed to provide the network with a list of those individuals managing their GIS activities.

The authors thank Mark Byrnes and Chacko John, both of the Louisiana Geological Survey, and Jeff Williams of the U.S. Geological Survey for their technical reviews of this report. Several Louisiana State University students are thanked for their hard work, which involved some long hours; their responsibilities include digitizing, producing the required graphical user interface, programming, and assisting in data-set acquisition. Undergraduates Christina Hebert, Bill Foster, Timothy Skelton, and Jay Arnold were trained on Modular GIS Environment (MGE) and are digitizing contours and helping with day-to-day activities. Graduates Niranjan Chintam, Sudish Mogli, and Srinivas Lingineni work exclusively on developing the menu interface, while David Peterson helped with system management. 


\section{TABLE OF CONTENTS}

ABSTRACT $\ldots \ldots \ldots \ldots \ldots \ldots \ldots \ldots \ldots \ldots \ldots \ldots \ldots \ldots \ldots \ldots$

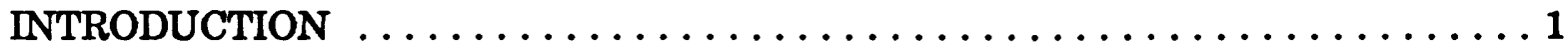

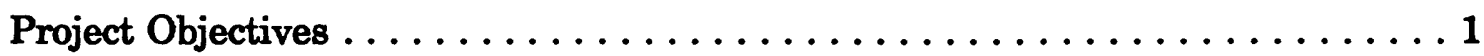

PROGRESS FOR YEAR TWO $\ldots \ldots \ldots \ldots \ldots \ldots \ldots \ldots \ldots \ldots \ldots \ldots \ldots \ldots$

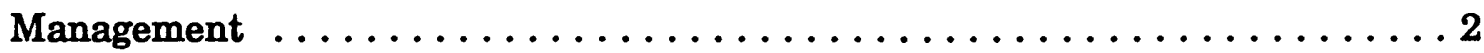

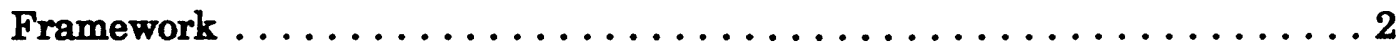

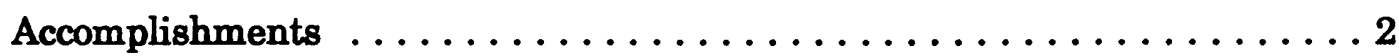

Technical Accomplishments $\ldots \ldots \ldots \ldots \ldots \ldots \ldots \ldots \ldots \ldots \ldots$

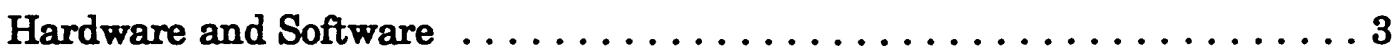

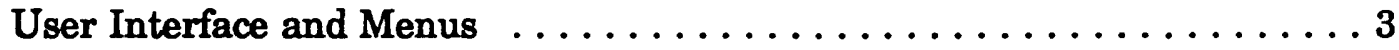

Search Criteria ..........................

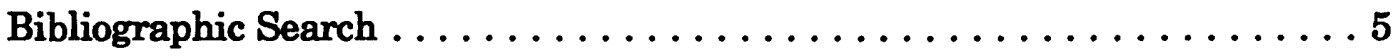

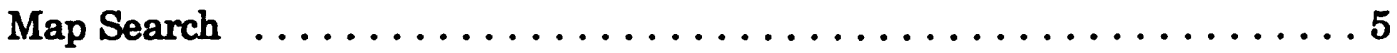

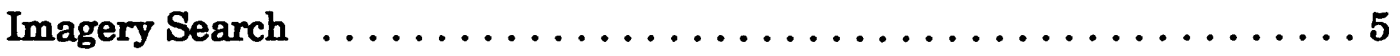

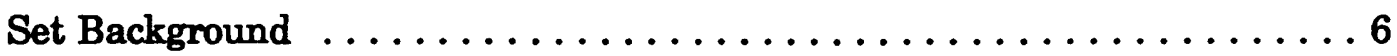

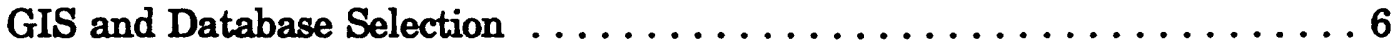

Acquisition of Existing Digital Data Sets $\ldots \ldots \ldots \ldots \ldots \ldots \ldots \ldots$

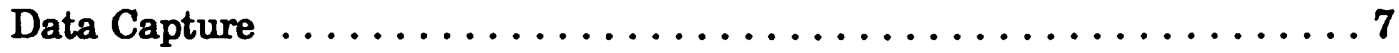

Bibliography and Cataloging $\ldots \ldots \ldots \ldots \ldots \ldots \ldots \ldots \ldots \ldots$

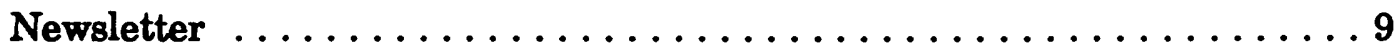

Technology Transfer . . . . . . . . . . . . . . . . . . . . 9

Technical Meetings and Conferences .................. 10

SUMMARY AND FUTURE DIRECTION $\ldots \ldots \ldots \ldots \ldots \ldots \ldots \ldots \ldots \ldots \ldots$

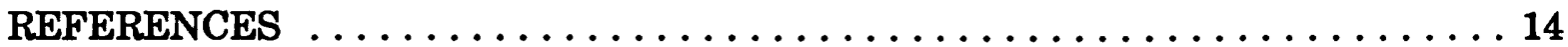

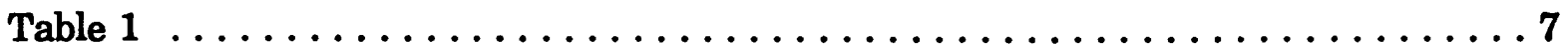




\section{INTRODUCTION}

In response to Louisiana's coastal land loss problem, the U.S. Geological Survey (USGS) in cooperation with the Louisiana Geological Survey (LGS) and Louisiana State University (LSU) established a research initiative to investigate the process-response mechanisms of barrier island erosion and wetland loss. Moreover, other local, State, and Federal agencies are studying and mapping additional natural and cultural resource characteristics of the coastal zone. The products of these various research endeavors are compiled into one of the United States' largest multi-disciplinary coastal data bases. Considerable data have been collected, analyzed, and archived; however, much of the information is not catalogued properly or linked efficiently to an electronic data base. These data include digital maps, high-resolution seismic profiles, vibracores, aerial videotape surveys, satellite imagery, tabular records, high- and low-altitude photography, and field surveys. Unfortunately, much of the digital data is unknown or inaccessible to other agencies because of storage media, data structures, or hardware platforms. To organize these diverse, multi-agency data sets into an automated system for the coastal zone of Louisiana, the USGS has committed funds to establish the LCGISN for data access and retrieval.

During the first year (September 1989 to August 1990), the network targeted three categories: 1) coordination, 2) technical achievements, and 3) hardware, software, and networking decisions. To coordinate diverse elements with ongoing research, a management council was organized. In addition, the Louisiana GIS Task Force and Remote Sensing and GIS Coordinating Council invited LCGISN to participate in their managerial activities.

A data decision workshop was held to identify the most important data sets for Louisiana's coastal zone. Sixteen representatives from various local, State, Federal, and university organizations attended the half-day workshop. Two other important issues were addressed: 1) the development of an on-line link to standardized bibliographic records, index maps, and vector and raster data, with the ability to automatically access these records; and 2) the design of a prototype menu interface to provide easy access to a wide variety of users. Furthermore, two GIS software packages were acquired (Intergraph Modular GIS Environment and ESRI Arc/Info) and linked to the LSU campus-wide Ethernet.

\section{Project Objectives}

The primary objectives of the network are as follows: 1) improve communication among coastal scientists; planners; land managers; local, State, and Federal agencies; and private groups who need information to address Louisiana's land loss problems; 2) simplify the integration of environmental data from various sources; 3) eliminate the duplication of effort so research and restoration funds can be spent efficiently; 4) identify the most important data bases available and incorporate them into the GIS network; 5) promote the development of networks and digital data exchange among hardware and software platforms, systems, and institutions that use coastal information; 6) promote the establishment of uniform data exchange formats and data quality standards; 7) develop universal guidelines for cataloging different media (maps, photographs, satellite imagery, videotape surveys, textual attributes) and establish data set ancestry criteria; 8) develop 
a user interface that provides easy access to spatial data; 9) publish a newsletter; and 10) assist other organizations in developing effective GIS strategies. Overall, LCGISN is not another GIS but a computer network that supplies the user community with a mechanism to access geographic information.

\section{PROGRESS FOR YEAR TWO}

\section{Management}

During the second year of funding (September 1990 through August 1991), management activities focused on project integration, menu development, hardware and software purchases, graduate and undergraduate education through project participation, data set acquisition, and a revised administration procedure.

\section{Framework}

Internal management of LCGISN was separated into four primary components: 1) project management, 2) GIS/network management, 3) GIS applications, and 4) project support. To ensure continued systematic development of LCGISN, the Technical Group identified several fundamental tasks to be addressed. Because of increased technical and coordination activities, project management was modified to encompass a technical coordinator and an operations coordinator. Randy McBride assumed responsibility for the project's technical aspects. As a co-principal investigator on the LCGISN project, $\mathbf{M r}$. McBride supervises and coordinates the project's technical meetings and weekly activities, menu development, and programming. Dr. Donald Davis serves as operations coordinator. He attends interagency meetings and supervises project operations, budget matters, and personnel issues. Dr. Davis is responsible for overall project operations and properly coordinating all of the diverse elements of the project. Farrell Jones, GIS/Network Manager, is responsible for system development and efficient operation of the network. He advises management on hardware and software design, types of applications, timing for data input to the network, and technical personnel needs. In addition, the GIS/Network Manager works with Decision Associates on menu development and implementation. The GIS applications group, led by Matt Hiland, is responsible for coordinating GIS development and data needs of the network with Farrell Jones, Randy McBride, and Don Davis. Project support personnel are responsible for compiling and digitizing data under the direction of applications personnel. This includes student workers for digitizing and library science personnel who assist in cataloging to develop a carto-bibliography and spatial index.

\section{Accomplishments}

In the second year, the Technical Group was able to accomplish several previously estabhished goals: 1) begin building the menu interface; 2) initiate programming efforts; 3) select Intergraph Modular GIS Environment (MGE) as the operational GIS using Oracle as the relational database management system; 4) produce bibliographic and cataloging work sheets using international cataloging standards; 5) contact numerous foundations for additional funding; 6) submit a proposal to British Petroleum for possible foundation funding to help with cataloging; 7) publish and mail the first LCGISN Newsletter to over 600 individuals in April 1991; 8) attend technical meetings and conferences, either as presenters or participants; 9) construct and present a poster display 
at numerous GIS-related functions; 10) sign an intergovernmental work-share agreement between the USGS National Mapping Division and LGS for digitizing the 310 USGS 7.5min. quadrangle maps within Louisiana's coastal zone; 11) digitize 37 quadrangles; 12) interact with organizations that use and generate digital data sets; 13) host a Management Council meeting in April 1991; 14) continue to participate in the meetings of the State GIS Task Force and the LSU Remote Sensing and GIS Coordinating Council; 15) hold a half-day LCGISN session at the Seventh Annual RS/GIS Workshop in New Orleans, with the technical and coastal users advisory groups; 16) prepare a list of critical factors to consider for LCGISN database selection; and 17) collect and archive information on several on-line data bases.

\section{Technical Accomplishments}

\section{Hardware and Software}

Intergraph I-Forms, a software package used to create screen menus, was purchased to aid in menu development. An Intergraph Interserve 6105 server, with extensive expansion capabilities, was purchased as the primary data storage and processing unit for the network. The equipment has been received, connected to the LSU Ethernet and is currently storing several data sets. The two Sun Sparcstations are being used for Arc/Info applications. The workstation in the LSU Department of Geography and Anthropology is being used for several student-oriented Arc/Info and ERDAS projects, while the workstation at LGS is being used as a secondary server.

The hardware and software purchased in Year Two are listed below:

- Intergraph InterServe 6105 server

- Two copies of MicroStation PC

- One copy of MicroStation Mac

- Intergraph I-Forms application development software package

- C compiler for use with I-Forms

\section{User Interface and Menus}

A great deal of effort went into developing a prototype user interface, including interface design and choices necessary to provide the user with an easy and powerful means for accessing geographic and textual data. The Technical Group worked under the premise that the project goals should drive system functions and in turn drive interface design. Decisions regarding which choices to present to the user would further refine the functions the system should execute. To provide a high degree of flexibility and utility, the design was prototyped during the first year using the HyperCard system on a Macintosh computer.

Development of the prototype menu system began with a list of general functions the Technical Group thought were essential:

- Provide basic information about LCGISN and on-line help facilities for using the system,

- Provide a directory of affiliates and associates involved in coastal activities within university, government, private, foundation, and non-profit organizations, 
- Maintain computerized bibliographic records of publications pertaining to coastal Louisiana,

- Develop a spatial indexing and geographic search system for maps, photographic products, and imagery, and perform interactive searches as specified in a variety of menu choices,

- Provide display and query capabilities of LCGISN primary GIS digital data bases with minimal spatial calculations and statistical analyses,

- Provide the capability to convert data from one GIS to another,

- Provide coordinate system and projection transformation capabilities,

- Allow user customized procedures and customized environments,

- Provide electronic mail and other convenient utilities.

Based on these primary functions, a more detailed, menu-oriented user interface was derived to prototype concepts. Hierarchical menus were developed through weekly mangs of the Technical Group. From these meetings, the prototype evolved to its rent state. Each concept or concept group was given major emphasis by allocating it separate menu accessible from the main menu. Personnel from the Technical Group were assigned to develop the ideas and functions within each primary sub-menu accessed from the main menu.

Foremost in the minds of the designers was a user interface that had a standard language, avoided deep menus (i.e., the necessity to make many choices to obtain the desired result), and was simple. The menu path needed to be short; consequently, the Technical Group strived for a balance of many concepts:

- User friendliness vs. capabilities of the system,

- Non-technical verbiage vs. precise technical language,

- Use by non-technical and casual users vs. complex use by scientists and researchers,

- Simplicity vs. high level of detail,

- Generalized interface vs. reduced levels and number of menus,

- Default input vs. user control.

The system's functions were outlined in detail, reviewed, modified, and developed into hierarchical menus constructed in HyperCard. The menu system was developed in a prototype environment to provide the Technical Group with a first-hand look at how the system will operate. The final user interface will be generated and implemented using Intergraph I-Forms software, which enables a programmer to build effective menus and link them to Intergraph graphics (MicroStation) and GIS (Modular GIS Environment) software using MicroStation Development Language (MDL) and the programming language C. Although refinements will be made, more than half of the 65 menus designed by the programmers have been completed.

The heart of LCGISN is the ability to search for and find data relevant to the needs of the user. To ensure the accessibility of each piece of information, many different search methods have been included. Each entry will have a record similar to a bibliographic record in a library system, including title, author, date of publication, etc. This will allow all normal bibliographic search methods to be performed. Where possible, entries also 
will have a unique indicator of geographic location, based on geo-coordinates or regional names, so a spatial search can be performed. This will allow the user to find all information in any given area. Also, bibliographic and spatial searches can be combined to provide a mechanism for access to textual and spatial data.

Following are brief descriptions of some of the menus and options in the user interface. These are intended to illustrate the flexibility of search methods, ease of use of the system, and thoroughness of data type criteria included for performing searches.

\section{Search Criteria}

The search criteria menu is the initial step in defining a query (Hiland and others, 1991). Selections are available for performing bibliographic and geographic searches for textual material as well as maps, satellite imagery, photography, video, and general or specific survey data. Also available are buttons that specify a search only for digital data or non-digital data only. The text output only button allows the user to create a list of references to data without actually displaying graphics files. LCGISN main only searches only for those data sets identified as critical and physically stored at the network facility. Set background displays maps that assist the user in defining the geographic area of interest, which is accomplished through the specify location button. Some of these functions are described in more detail below.

\section{Bibliographic Search}

Upon choosing the corresponding select button, the bibliography select menu appears. This menu allows the user to select all bibliographies that have been downloaded or to choose which bibliographies to query. The same holds true for carto-bibliographies. After choosing the sources to search, the bibliographic search criteria button is selected. This will display a form with selections for author, title, and key word searches. These options will then produce a form with key-in fields for each. The input to these forms will be compiled internally into a Standard Query Language (SQL) query and processed, returning a list of all records that fit the criteria defined.

\section{Map Search}

The select button produces a menu with criteria by which to search for digital and/or non-digital maps, according to selections made on the search criteria menu. The user may search for maps by a specific publisher, of a particular theme, or at a certain scale. Furthermore, maps can be found according to a specified date or a range of dates as well as by map projection or coordinate system. Digital maps that meet all search criteria and are available on the network will be listed on the screen. Maps selected from this list may be displayed, converted between coordinate systems, transformed between formats, and/or imported to the user's system. Other maps will be listed as bibliographic references. Also included will be information on the owners of these maps and contact persons for obtaining them.

\section{Imagery Search}

The imagery search menu includes specifications for cloud cover, season, date, quality, format, source, scale, and product type. The query defined in this menu searches for digital imagery and hard copy of images. The user may choose to search for imagery in all digital formats or select specific ones, such as ELAS, ERDAS, EOSAT, etc. 


\section{Set Background}

When the set background button is selected, a menu with display options will be displayed along with a default base map of the Louisiana coastal zone. This base map will include a current shoreline derived from thematic mapper data, political boundaries, USGS 7.5-min. quadrangle map boundaries, and major transportation networks. The user can then choose from several other data sets, turning on and off themes and layers to create a background map that will allow the user to more precisely define the area of interest. The available background themes include the default settings mentioned plus National Wetlands Ecological Characterization maps, salinity maps, land-use maps, USGS Digital Line Graph (DLG) data, USGS 7.5-min. quadrangle maps, and others.

\section{GIS and Database Selection}

The Technical Group developed a list of critical factors for GIS evaluation and began primary assessments of the candidate GIS (Table 1). After evaluation of Arc/Info, InfoCad, and MGE, along with Oracle, Ingress, and Informix as the associated relational data bases, the Technical Group chose the Intergraph Modular GIS Environment (MGE) as its operational GIS and Oracle as its relational data base.

\section{Acquisition of Existing Digital Data Sets}

The U.S. Army Corps of Engineers provided LGS and LCGISN with four quadrangles from their digital-land-loss data base. The remaining data will be supplied at regular intervals. All maps will be at LGS by early to middle 1992. Other data sets have been identified and tentative agreements have been reached to incorporate them into the network. In some cases, these data sets are already available through the CADGIS Laboratory archives. Soil associations, U.S. Census Bureau TIGER files, offshore oil wells and hazards to navigation are a few of the records that are available through CADGIS. The National Cartographic Information Center is providing a catalog of satellite imagery and aerial photography. Contacts also have been made with the U.S. Fish and Wildlife Service in Slidell, Louisiana, to acquire data from their agency.

LCGISN has received the following digital and non-digital data sets: 1) Aerial Photography Summary Records System (APSRS) from the National Cartographic Information Center on CD-ROM and on microfiche for Louisiana; 2) Geographic Names Information System (GNIS) from USGS for Louisiana on microfiche and hard copy; 3) OCLC on CD-ROM for publications in Middleton Library; 4) geographic publications from American Geological Institute (AGI) on CD-ROM; 5) microfiche of radar coverage in Louisiana and elsewhere; 6) Gloria data for the Gulf of Mexico on CD-ROM, Digital Line Graph (DLG) data for the United States, and digital radar data on CD-ROM from the USGS; and 7) the Maps and Chart Information System (MCIS) microfiche containing latitude and longitude and alphabetic files for Louisiana. A bibliography is being compiled on GIS activities nationwide. CD-ROM data is accessible through CD-ROM readers, available at the LCGISN Intergraph server.

The Technical Group received documentation from David Stage, Staff Director for the Florida Governor's office. This report, the Data Dictionary on Quality and Accuracy, presents standards for submitting GIS citations. The Florida approach may be an asset for LCGISN. A modified or a revised version of this document could be distributed to Louisiana organizations compiling a list of their holdings. 


\section{Table 1. Critical Factors in Selection of GIS for LCGISN}

(Hiland and others, 1991)

- Ability to add new functions and/or commands from within the GIS using a high-level programming language

- Ability to interface to a commercial relational data base

- Ability to display raster images

- Structured Query Language (SQL) interface, ad hoc front end, or 4GL interface to data base

- X-Windows server support

- Multiple users' read-only access to GIS data base

- Feature layering associated with graphic overlay display

- Network File System (NFS) and server support

- Functions under UNIX Operating System

- Simultaneous display of vector and raster data

- Interactive map query facility

- The ability to interface to the GIS or subsystem of the GIS from UNIX

- Custom menu facility

- Map organization, tiling and systematic retrieval facility

- Scale dependent suppression of data, grids, and text

- Display speed

- Database query and retrieval speed

- Speed of important spatial functions

- GIS and database conversion utilities

\section{Data Capture}

Bill Good and Harold Fiebelman (USGS Mid-Continent Mapping Center, Rolla, Missouri) visited LSU in December 1990. As a result of this meeting, an intergovernmental work-share agreement to digitize elevation contours has been signed and implemented. Thirty-seven, 7.5-min. quadrangle maps have been digitized following strict USGS standards. This project uses an Intergraph workstation located in the CADGIS Research Laboratory. The decision to use this workstation was based on availability and suitability for running the RETSAM-32 software. USGS developed RETSAM-32, a program designed to work as an add-on module to Intergraph MicroStation 32, version 3.3. RETSAM-32 controls the digitiving and attributing of line work, and with further processing, the line work can be converted and stored in DLG 
format. Students are using streamline digitizing parameters for data capture. Digitizing of the test quadrangle began in March 1991, with LCGISN exceeding the expectations of the USGS Mid-Continent Mapping Center. A current computer work flow is in place, and USGS is providing sets of 16 bromide-based maps at regular intervals. The third set of maps is being digitized now. Thirty-two maps have been sent to Rolla, Missouri, for review.

Carl Nelson from USGS in Rolla, Missouri, visited for one week in July to assist in understanding proper USGS digitizing techniques, the functionality of USGS RETSAM 32 software, and work-flow parameters employed by USGS in digitizing maps for making Digital Line Graphs (DLG). His assistance was very valuable and has led to accelerated and smooth progress. As of September 1991, hypsography had been collected for 37 of the 7.5-min. quadrangle maps.

In March 1991, portions of coastal Louisiana were covered with Side-Looking Airborne Radar (SLAR) and the unrectified imagery is available through the LGS. Radar coverage was completed in the summer of 1991. Field data were collected by several State and Federal agencies in concert with the overflight. Consequently, the digital and hard copy radar data and related data sets will be available within a year and should be an important data base in the LCGISN archives.

Members of the Technical Group spoke with the Louisiana Department of Natural Resources Information Processing Services Division about sharing data. It became apparent that it may be useful to institute some type of data-sharing contract. The primary concept is the inclusion of a map credit file that notes the map or GIS product sources, developers, and modifiers. Whenever a map is used, this information is displayed-similar to the credit lines used to reference a journal article or a technique. The credit file will document the GIS product history and identify the individual or agency that produced it. The system will contain at least seven possible types of data:

- Index or catalog of data,

- Maps that can be used to set the background, thereby allowing the user to orient,

- LCGISN primary data bases located on the LCGISN server as identified by a Data Set Decision Workshop that included Federal, State, and university agencies,

- LCGISN primary data bases located remotely,

- Data identified by the catalog, but unavailable through the network,

- Data identified by the catalog and located on the LCGISN server,

- Data identified by the catalog and available remotely via network file server (NFS)

Farrell Jones has begun moving many files that have accumulated at the CADGIS Research Laboratory and at LGS to the server. The files are stored under a filing scheme consistent with current mapping and GIS software in use at the CADGIS Research Laboratory and LGS. The scheme will also facilitate the retrieval of digital data by the LCGISN menu interface currently being developed. 


\section{Bibliography and Cataloging}

In December 1990, the Technical Group met in Middleton Library to discuss map indexing and cataloging protocol and procedures with library staff. From this meeting, the committee familiarized itself with standardized library data input and standards. Based on this meeting and international bibliographic cataloging standards, Information Research created cataloging work sheets. Information Research's final report was provided in December 1990. We are also investigating the license agreement required to be a part of the LSU library NOTIS system. One of the first items that will be added to the LCGISN data base will be a large digital bibliography that includes a partial listing of LGS holdings.

Because the bibliography task is extensive, a letter was mailed to 35 foundations requesting funding information. Additional funding is critical to help meet the objectives of this ever-growing task. Only a few foundations responded; however, British Petroleum America is considering our request for funds to assist in underwriting the cost of building the bibliography data base.

In working with the bibliography issue, the Technical Group focused on developing the proper liaison with the staff of Middleton Library. Dr. Michael Carpenter, Assistant Professor, LSU Department of Library Science and Information, was invited to direct LCGISN bibliographic objectives. His expertise is cataloging and the use of the international bibliographic exchange format MARC. Beginning in Year Three, several months of his time will be dedicated to the project, and a graduate student in library science will be added to the budget.

\section{Newsletter}

The Technical Group decided that the LCGISN Newsletter will be published twice a year (April/May and October/November) and will be devoted to short articles, conference announcements, and LCGISN updates. The first newsletter was published and distributed; it included material from Bo Blackmon, John Barras, Larry Handley, Dewitt Braud, Randy McBride, Farrell Jones, Jeff Williams, and Richard Larkin. Issues of the newsletter are printed on recycled $11^{\prime \prime} \times 17^{\prime \prime}$ paper folded to $8.5^{\prime \prime} \times 11^{\prime \prime}$, with an $8.5^{\prime \prime} \times 11^{\prime \prime}$ insert to total six pages.

\section{Technology Transfer}

Interest in the network is rapidly expanding, with local, State, Federal, and private organizations wanting to participate. The State GIS Task Force is considering using the concept of LCGISN as the foundation for their statewide effort because they may develop a GIS clearinghouse for State-related digital data at Middleton Library.

To visually explain the purpose and function of the network, the Technical Group designed a poster display. The existing HyperCard menus were printed for the display and examples of maps, imagery and data were printed to be used as samples of output from the system. The final design was presented to the Technical Group for comment and review. The materials were given to the Cartographic Section for specific layout and production of the final version. Considerable effort was expended on producing final plots of the maps and imagery for the poster. This was accomplished largely through the assistance of the Department of Natural Resources Information Processing Services Division. 
This visual presentation was used on numerous occasions, including the April 1991 Management Council Meeting, the Seventh Annual RS/GIS Workshop in New Orleans, the EPA Gulf of Mexico GIS Conference in New Orleans, and a full meeting of the State GIS Task Force in Baton Rouge. Furthermore, the editors of Meridian requested material on LCGISN for inclusion in a special issue devoted to the use of maps and spatial data. The short article, "Louisiana Coastal Geographic Information System Network," appeared in Meridian No. 5, 1990 (McBride and others, 1990). More recently, a complete manuscript was submitted to Meridian for publication (McBride and others, 1991).

Farrell Jones conducted a week-long workshop on UNIX/Intergraph operating systems for the Department of Transportation and Development to familiarize the user community with the system's functionality.

Discussions were held with Steve Little of Exxon concerning an LCGISN demonstration. There is considerable oil industry interest in GIS applications in oil spill emergencies. It is conceivable this interest will impact LCGISN. As the petroleum industry increases its catalogue of spatial data and develops systems with networking capabilities, LCGISN may become their data management model.

Ken Haddard, Environmental Administrator in Florida, was contacted because of his interest in data sharing and data exchange between different geographic information systems. He is particularly interested in the Federal Spatial Data Transfer Standards and how Florida can work with the network. Subsequently, Charles Palmer with the Texas Natural Resources Information System and Pat Bigelow with the Alabama GIS/LIS Information Exchange Group were contacted about working jointly on building an on-line Data Directory, with LCGISN serving as one node on the network.

The Technical Group has sent a list of data attributes to be placed on the EPA Gulf of Mexico bulletin board and requested members on the bulletin board to contribute other items, so LCGISN can accumulate a super-set of attributes. We will then attach MARC codes to each attribute, so all States can standardize them and thus facilitate catalog exchange.

A member of the Technical Group visited Barksdale Air Force Base in Shreveport to meet with Air Force personnel and Dr. Ernest Kistler, Chief of the Systems Division. The meeting focused on the Air Force Model Base, a system designed to test ideas for automated computer systems before they are adopted by the Air Force. They are currently testing a GIS package for base facility and emergency management. Dr. Kistler is interested in data sharing and in solving problems associated with exchange of data among systems in a network computer environment. He has done some work in this area and made a presentation on his concept of a global schema and a smart box that handles data sharing in a network environment. The concept driving LCGISN fits into the Air Force data-sharing strategy. In Year Three, we plan to invite Dr. Kistler to LSU for a demonstration of LCGISN and discuss his involvement in network concepts and datasharing problems.

\section{Technical Meetings and Conference}

In December 1990, Don Davis met with the GIS Workshop Steering Committee from the EPA Gulf of Mexico Program in Slidell, Louisiana. From this meeting, a GIS Workshop was organized and took place in May 1991 in New Orleans. The thrust of the meeting focused on four goals: 1) a GIS introduction and needs assessment, 2) GIS 
activities in the Gulf of Mexico, 3) a network between managers and data generators, and 4) an agenda for future GIS work. One paper was presented on LCGISN.

In December 1990, Don Davis talked with Lisa Warnecke (Council of State Government, 256 Greenwood Place, Syracuse, New York 13210) about LCGISN. Ms. Warnecke is writing a report on the status of GIS activity by state. We sent her copies of other material related to LCGISN.

Don Davis attended the Jefferson and Orleans parishes seminar entitled, "Public access to records, products and services from GIS," that was held in February 1991 in Metairie, Louisiana. The conference focused on the following issues:

- Can local governments legally sell their data?

- If data are provided to a group, who is liable for any errors in the data set?

- All projects need an accurate base map that can be used by all parties participating in the GIS effort.

- Currently, public access is unlimited under the Freedom of Information Act.

- The question of access to public records is highly involved and Louisiana's Open Records Law implies that all data are to be provided to the public at the cost of copying the data.

- Public vs. private data sets, double taxation, reasonable access, and cost recovery.

In February 1991, Greg DeCote was contacted to promote participation of the State's coastal zone managers in the Seventh Annual RS/GIS Conference in New Orleans. LCGISN had a special half-day session at this May 1991 meeting. Sharon Balfour and Nelson May chaired the LCGISN advisory committees.

In February 1991, Henry Streiffer of Decision Associates visited Dan Holmes of the University of California-Berkeley to discuss ImageQuery, a similar computerized spatial information system. Mr. Streiffer was impressed with the effort, but he was also skeptical. First, ImageQuery only works with raster images and does not handle them well. During operation, three windows, a main screen, a geo-referenced image, and a third, with a spreadsheet containing database hits, are active and visible. These windows were interactive in that by selecting one of the hits, the corresponding dot in the image window was highlighted. Further, if a user selected a point or group of points in the image window, the corresponding hits were highlighted in the spreadsheet window. This is a very effective and user-friendly approach that should be incorporated into LCGISN.

FileMaker software running on a Macintosh computer is used to put data into the Berkeley system, after which data are moved to a UNIX workstation. The developers have included a nice pan and zoom feature in the image window controlled by another window. Ingres serves as their relational data base.

ImageQuery runs on UNIX workstations, Sun, VAX, IBM and the Mac under UNIX. It is a good system, but there are some drawbacks. First, the system does not handle vector data-a must for LCGISN. Secondly, all of the ImageQuery software was developed in-house under X-windows. LCGISN does not have the personnel to undertake this type of programming effort. Consequently, the Technical Group is using I-Forms, MGE, and other commercial packages. From the demonstration and discussions, it is apparent that LCGISN is further along in actual design than the Berkeley work. 
In March 1991, members of the LCGISN technical committee (Matt Hiland, Henry Streiffer, Niranjan Chintam, Randy McBride, Dewitt Braud, Don Davis, Farrell Jones, and Tony Lewis) participated in a special half-day Oracle Seminar entitled, "The Client/Server Forum." The seminar was held at the Westin Canal Place in New Orleans and involved multi-media presentations and live demonstrations on how to implement open client/server database applications on any platform. Discussions focused on database development, new network technology, hardware and software configuration, and technical support.

Tony Lewis organized and hosted, in March 1991, a seminar on the Louisiana radar mapping program. In August 1991, he was invited to participate in the Landsat Users Meeting at NASA headquarters, Washington, D.C. At both of these meetings, elements of the LCGISN were discussed. Furthermore, in September 1991, Dr. Lewis presented a paper on the LCGISN project for the American Water Resources Association's (AWRA) Annual Meeting in New Orleans.

Matt Hiland and Farrell Jones attended the Intergraph Graphics User Group (IGUG) meeting held in Huntsville, Alabama, during May 1991. At this meeting, Farrell Jones attended sessions covering system and network topics such as new system upgrades, current network problems and solutions, and programming with the MicroStation Development Language (MDL). Matt Hiland attended sessions covering mapping topics such as upgrades to existing mapping software, new mapping products, and future directions in application capabilities. Two products were of particular interest; one is the I-Geovec software which is a line-following vectorization software package that integrates with MGE, and the other product is tentatively titled GeoFile. This package performs library functions on graphics and database information of digital maps.

In August 1991, Decision Associates attended the GISDEX Conference in Washington. The conference covered a wide variety of GIS activities in the Federal Government. In addition, there was a call for certification of GIS vendors and consultants. The most important find was a demonstration of an automated digitizing system (VTRAK) developed by Laser Scan Incorporated.

Decision Associates also met with individuals at the National Space Technology Laboratories at Bay St. Louis, Mississippi. These discussions focused on radar data and the SPANS system - a NASA-based information system. At the Office of Naval Research, a raster-based World GIS and MUSE (a standardized utility software environment) were investigated. While at the National Cartographic Information Center, a demonstration of IDRISI, a PC-based GIS, and ROOTS, a PC-based digitizing system were provided.

\section{SUMMARY AND FUTURE DIRECTION}

LCGISN represents an information access system that provides users a mechanism for integrating spatial and textual data from multiple sources for Louisiana's coastal zone. Organizationally, it consists of a management council, network core group, technical GIS group, and two independent advisory groups (coastal users and technical/applications). One of the top-ranked data sets identified for inclusion in LCGISN is a spatial index/bibliography for available data relating to Louisiana's coastal zone. Such an index will link true geographic location to maps, imagery, photographs, names, and bibliographic references to allow spatially defined geographic searches. An essential 
function of LCGISN is to connect any existing GIS and provide user access to spatial data available in different types of media.

To date, the prototype user interface has been designed, tested, and refined using HyperCard running on a Macintosh. Unix-based workstations and GIS software were acquired, and the network core group was connected through the LSU campus-wide Ethernet. The Management Council and two independent advisory groups were established and integrated with LCGISN. Implementation of the user interface onto Unix-based workstations running $\mathrm{X}$-windows is in progress. The major data sets identified and ranked will be further assessed and, where possible, imported into the system. In the future, work will focus on perfecting the user interface, importing additional digital data sets, acquiring or programming translation routines, cataloging various types of media, developing a computer bulletin board, and regularly publishing a newsletter. 


\section{REFERENCES}

Hiland, M.W., McBride, R.A., Davis, D.W., Braud, D., Jr., Jones, F.W., Lewis, A.J., and Williams, S.J., 1991, Louisiana Coastal GIS Network: Graphical user interface for access to spatial data, GIS/LIS '91, American Society of Cartography and Mapping, Washington D.C.

McBride, R.A., Davis, D.W., Jones, F.W., Braud, D., Jr., Lewis, A.J., Streiffer, H.R., Penland, S., Lam, N.S.N., and Williams, S.J., 1990, Louisiana Coastal Geographic Information System Network (LCGISN): Meridian, v. 5, p. 57-59.

McBride, R.A., Davis, D.W., Jones, F.W., Byrnes, M.R., Braud, D., Jr., Hiland, M.W., Lewis, A.J., and Streiffer, H.R., 1991, Louisiana Coastal Geographic Information System Network (LCGISN): Access to spatial data: Meridian, v. 6, p. 29-43. 